\title{
VICTORIA OCAMPO, UNA ARGENTINA UNIVERSALISTA
}

El último domingo de enero, en uno de los días más luminosos del verano, las pocas personas que estaban en Buenos Aires fueron al entierro de Victoria Ocampo, en la Recoleta. En realidad, nadie podía creer que hubiera muerto. Hacía tiempo que estaba enferma y en el otoño anterior había sufrido una fuerte recaída, cuando murió la querida y lamentada Fryda Schultz de Mantovani, su amiga entrañable. Luego mejoró: pudo todavía, desde San Isidro, retomar la dirección de Sur. En agosto del año pasado ya no se levantaba y recibía en cama. En dicienbre, ella, tan amante de escribir cartas, dejó de contestarlas. Sin embargo, nadie esperaba ese desenlace.

Si bien es cierto que había pocos escritores en el sepelio, el peristilo de la Recoleta estaba lleno de espontáneos, gente que, sin conocerla, la admiraba y había ido a rendirle un homenaje, porque sentía que tenía una deuda con ella. No en vano, Borges dijo: "Personalmente le debo mucho a Victoria Ocampo, pero le debo mucho más como argentino.» Comentando su muerte, Borges confesó: «En un país y en una época en que las mujeres eran genéricas, tuvo el valor de ser un individuo... Creo que Victoria Ocampo fue una mujer de Ibsen. Vivió, con valentía y decoro, su propia vida. Su vasta obra, en la que abunda la protesta, no condesciende nunca a la queja. Se dedicó a la educación de su país y de su continente. Aunque no profesó, o acaso porque no profesó, ciertas supersticiones que ahora se creen indispensables, fue profundamente argentina:»

La primera vez que vi a Victoria Ocampo fue en la Sociedad Argentina de Escritores, en la vieja casa colonial de la calle México. Ella estaba sentada en el estrado del salón de actos, a la izquierda de su propio retrato, que la mostraba joven, hermosa y lejana, enmarcado románticamente el rostro por un gran sombrero. Yo, todavía adolescente, observaba aquellos dos rostros que tenía enfrente, y en mi devoción por Victoria, a la que admiraba incondicionalmente, como sólo se puede admirar 
cuando uno es muy joven, componía con ambas imágenes una sola. La mujer madura (bordeaba por aquella época los sesenta años), grande, casi majestuosa, elegantísima, de piel transparente y cuyo adorno más visible eran unas florecitas prendidas con prolijo descuido a la solapa de su traje, se superponía a su retrato. Ese primer contacto, decisivo para mí, ocurrió el anochecer del 13 de junio de 1951, cuando ella recibió y agradeció el Premio de Honor de la SADE (Sociedad Argentina de Escritores) 1950. La transcripción de unos pocos párrafos de aquel discurso memorable bastarán para mostrar no sólo el carácter invencible de Victoria, sino también para apreciar cómo era el estrechísimo mundo en que comenzó su vida. «... Cuando Borges me anunció esta decisión de la SADE, pensé, sin haber vuelto de mi asombro: y ahora, ¿les fabricaré un discursito de agradecimiento convencional o les diré lo que realmente siento?... He optado por lo segundo... Les hablaré de un tema que es de los pocos que conozco a fondo... Los obstáculos que se interponían entre una mujer de mi época, de mi país, de mi clase, y la carrera que resolví seguir por inclinación natural..., y las condiciones de manifiesta inferioridad que encontraba una muchacha, rica o pobre..., en lo que concernía a su instrucción. Se enseñaba gramática (léase ortografía), aritmética elemental, mucho catecismo, historia sagrada, un poco de historia universal, otro poco de historia argentina, algunas vagas nociones de ciencias naturales, idiomas, especialmente francés e inglés. Añádase en nuestro caso la lectura de trozos escogidos, la obligación de aprender de memoria unas cuantas fábulas, poesías o trozos de los grandes clásicos y piano... Nosotras, mis hermanas y yo, tuvimos la suerte de caer en las manos de una institutriz francesa, rigurosa, puntual, inflexible y sabiendo muy bien lo poco que sabía..., que nos hizo leer bastantes clásicos franceses..., y me aficioné a ellos... Nuestra maestra de español nos obligaba, en cambio, a lecturas de un aburrimiento siniestro... Miss Ellis, la maestra de inglés, conquistó nuestro corazón a través de Dickens, pero el francés quedó como punto central de nuestra educación... Desde los nueve años, escribir me pareció un desahogo... y mi primer escrito fue una defensa de los bóers (en contra del Imperio Británico) en la guerra del Transvaal. Nuestra Miss Ellis, un cordero de mansedumbre, a fuerza de machacar historias a favor de sus compatriotas, logró ese brillante resultado. Ejemplos de los riesgos de una propaganda mal dosificada... En mi adolescencia, después de oír recitar a Marguerite Moreno, descubrí que mi verdadera vocación era el teatro...; tomé lecciones con ella, sabiendo de antemano que los prejuicios de la época me harían renunciar a esta vocación... El descubrimiento del De profundis de Oscar Wilde, bajo mi almohada, alcanzó las proporciones de catástrofe y yo tenía die- 
cinueve años. Las niñas no salían nunca solas a la calle, no era bien visto que se carteasen o hablasen por teléfono con el novio. Montar a caballo en su compañía en Palermo, aunque fueran acompañadas por sus propios hermanos, era escandaloso...; el tango era indecente... se fumaba a escondidas... el rouge era de mal tono... a los veintidós años me despacharon de la mesa por haberme pintado levemente los labios... la generalidad de los escritores y artistas eran considerados con bastante recelo... Y si yo hubiera anunciado a mis padres la decisión de dedicarme a las letras, hubiera sido motivo de inquietud y cavilaciones. Llegué a la conclusión de que digerirían mejor los hechos consumados... Pero la publicación de mi primer artículo en La Nación no fue para mí, como debió ser, un día de franca alegría; fue un día de sol y nubarrones alternados.»

Como se desprende del texto citado, Victoria Ocampo, nacida en Buenos Aires en 1890, provenía de una familia de la clase alta, emparentada con las grandes personalidades de la historia y de la cultura del país. A fines del año 1977, cuando tuvo lugar en San Isidro el Diálogo de las Culturas, organizado por la Unesco, ella recordaba que, debajo de esa misma mesa del comedor, donde se desarrollaban las ponencias, se escondía a menudo, siendo muy chiquita, para escuchar a los próceres cuando iban de visita. Fue la mayor de seis hermanas: Angélica, Pancha, Clara, Rosa y Silvina, esta última cuentista y poeta y casada con Adolfo Bioy Casares. Uno de los orgullos de Victoria, un poco pintoresco si se quiere, era recordar que por el lado materno descendía de Irala, que allá por 1550 organizó la ciudad de Asunción del Paraguay, y de una india guaraní. A los seis años partió hacia Europa y vivió dos años en París. A su regreso, comenzó su vida de niña, que ella recordará muchas veces con reiterada nostalgia, del mismo modo que pocas o ninguna aludirá a su juventud y a su casamiento. Ese primer artículo, que ella mencionó en el fragmento transcrito, se publicó en La Nación en marzo de 1920; se titula Babel y es un comentario al canto decimoquinto del «Purgatorio» de la Divina Comedia. Siguiendo su vocación artística se presentó, junto a Ernest Ansermet, en una interpretación del David de Honnegger en 1925, y en 1936, en el Teatro Colón, recitó los versos de André Gide para la Perséfone de Stravinsky, dirigida por el compositor, actuación repetida luego en Río de Janeiro y en Florencia en 1939. Desde sus comienzos como crítica literaria no cesó de publicar notas en La Nación de Buenos Aires y en $E l$ Sol de Madrid. Viajó muchísimo y dictó conferencias en centros literarios de Europa y América. En 1925 publicó en Madrid la fábula escénica La laguna de los nenúfares. Fue fundadora del 
Pen Club de Buenos Aires y vicepresidenta del Congreso Internacional del Pen en 1930 y 1936.

Por aquellos años, estimulada por una de sus amistades literarias internacionales, el escritor norteamericano Waldo Frank, y por Eduardo Mallea, fundó en el verano de 1931 la revista Sur, bautizada telefónicamente desde Madrid por Ortega y Gasset. Sur inaugura toda una época en la literatura argentina. Tanto la revista como la editorial, fundada poco después, cumplieron una tarea cultural invalorable en la formación de los jóvenes intelectuales hispanoamericanos. Entre los muchos testimonios que así lo prueban, recuerdo una conversación con Vargas Llosa, en Alemania, en la que expresó la ansiedad con que en Perú aguardaban la llegada de Sur y del Suplemento Literario de La Nación, únicos vehículos periódicos que ligaban a su generación con la literatura universal. Y Julio Cortázar afirmó: «Sur nos ayudó a los estudiantes que en la década del 30 al 40 tentábamos un camino, titubeando entre tantos errores, tantas abyectas facilidades y mentiras.» Hace tres o cuatro semanas visitó Buenos Aires Rafael Conte, adjunto de la dirección del diario español $E l$ País y codirector de su suplemento literario, y recordó: «iQué deuda tenemos los españoles que nos educamos bajo el régimen de Franco con Sur! Muy caros, en las trastiendas de las librerías podíamos comprar y llevar a casa las ediciones argentinas de los grandes escritores contemporáneos: Camus, Malraux, Forster, Faulkner, que la generosa editorial de Victoria ponía en nuestras manos. Esos libros nos ligaban al mundo de la cultura.»

Sur cumplió una función de puente cultural entre los pueblos americanos y entre Europa y América, «un puente (al decir de la propia Victoria) que no fuera de una sola mano y que proporcionara a los sudamericanos la oportunidad de entrar en contacto con las grandes obras literarias del mundo actual».

Solía recordar Victoria que unos trece o catorce años después de la fundación de Sur, un periodista norteamericano le hizo un reportaje y le preguntó cuánto dinero ganaba con la revista. Ella le respondió que perdía con toda regularidad en cada número, y ante la exclamación "¡Pero eso no tiene sentido!», Victoria cuenta que, con gran paciencia ("aunque no era, precisamente, la paciencia una de mis virtudes», agrega entre paréntesis), le explicó los propósitos de la revista. En 1970, cuarenta años después de haber aparecido trescientos veintiséis números, en forma primero trimestral y bimestral luego, por razones económicas se publicó cada seis meses. Fueron sus secretarios de redacción Eduardo Mallea, Guillermo de Torre, José Bianco, Jorge Luis Borges, Raimundo Lida, Ernesto Sábato, María Luisa Bastos y Enrique Pezzoni. El último número 
de Sur, el 342, reúne todo el material presentado y discutido por los diferentes participantes en el Diálogo de las Culturas. Eligiendo; un poco al azar, nombres de quienes colaboraron en Sur, encontramos a Heidegger, Hermann Hesse, Thomas Mann, Henri Michaux, García Lorca, Guillén, Camus, Malraux, Romain Rolland, Forster, Virginia Woolf, George Bernard Shaw, Croce, Moravia, Piovene, Ungaretti, Faulkner, Saroyan, Nabokoff... La lista suma cientos de nombres y otra lista infinita conformaría la nómina de libros publicados por la editorial, que se estrena en 1933 con el Romancero gitano de García Lorca.

Borges, bastante tiempo antes de morir Victoria Ocampo, dijo: «Ella reúne dos virtudes que fueron, alguna vez, atributo del alma argentina: hospitalidad y valentía.» Borges tuvo razón, pero su hospitalidad se orientaba en dos sentidos. En su casa fueron recibidos de la mejor manera posible, por días, por meses o por años, desde Gabriela Mistral y los Ortega hasta Tagore, Graham Greene y Roger Caillois, pasando, nuevamente, por una lista infinita. Por otra parte, Victoria ha sido amiga incondicional de sus amigos. De su nutrida correspondencia quiero recordar dos: cartas, mejor dicho, dos fragmentos, de las muchas que intercambió con Paul Valéry. En una, fechada el 27 de abril de 1942 desde Vichy, en plena guerra, Valéry escribe: «Mi querida, mi buena Victoria, es éste un extraño 1lamado. iSigno de los tiempos! Mis dos pies vuelan hacia usted. Se atreven a implorarle. Aquí es imposible calzarse. ¿Puede usted hacerme hacer o encontrar un par de zapatos (negros, preferentemente) y quizá hacérmelos llegar por la embajada? Me haría un inmenso servicio..." Tres años más tarde, en mayo del 45, Valéry agrega en la posdata de una larguísima carta: «He recibido su carta, pero no el último café.»

Más allá de la hospitalidad que procede de la amistad está la del intelecto, que le permitió aceptar los infinitos temas propuestos por sus lecturas incesantes y recibir con entusiasmo las más diversas creaciones del mundo exterior. En la década del sesenta, antes de que los Beatles fueran un éxito, Victoria estaba profundamente interesada en lo que, en ese momento, ella denominaba «cuatro muchachos que van a marcar una época». Y cómo olvidar, por otra parte, su pasión por las películas de Visconti y los largos artículos que escribió aprobando o disintiendo con el maestro italiano.

La valentía, el coraje de Victoria también estaba situado en dos planos. Tuvo la sinceridad de transmitir y divulgar los temas literarios y artísticos con fervoroso entusiasmo, que provenía no sólo de la admiración, sino del análisis y de su voluntad «feroz y ferviente de aferrarse a la verdad», según dijo Eduardo Mallea. Precisamente por ese aferrarse 
a la verdad pudo demostrar su coraje civil. La revista Sur, las reuniones que allí se hacían, las actividades de su directora, los viajes de escritores, las conferencias, el trabajo ímprobo de una editorial que publicaba en español libros de habla inglesa, francesa o alemana uno o dos años después de haber sido editados en su lengua original, le valieron la animadversión de un gobierno amoral, que odiaba a los intelectuales porque no quería que nadie pensase por cuenta propia (signo inequívoco, por otra parte, de todos los extremismos de derecha y de izquierda), y así, en 1953, Victoria Ocampo fue a parar a la cárcel. También Norah Borges, pintora y hermana del escritor, fue encarcelada. Pero mientras la angélica Norah enseñaba los rudimentos del dibujo y de la pintura a las desdichadas compañeras de El Buen Pastor, casi todas prostitutas, Victoria, espíritu más práctico, las instruía en las artes imprescindibles y prosaicas de la limpieza e higiene personales. Dos años después recordaría el tiempo que pasó en El Buen Pastor: «En la cárcel uno tenía, por lo menos, la satisfacción de sentir que, al fin, tocaba fondo, vivía en la realidad... Te agradezco, Señor (se dice a sí misma), que me hayas concedido esta gracia. Estos temidos cerrojos, estas paredes elocuentes, esta vigilancia desenmascarada, esta privación de todo lo que quiero - y que yo padecía moralmente cuando aparentaba estar en libertad-, la padezco al fin materialmente... Siempre he querido la verdad por encima de todo, como si ella fuera la forma palpable de la libertad: pues bien, aquí la toco.»

Los gobiernos de Francia, Inglaterra, Italia, la Academia Francesa, la Universidad de Harvard, la de Visva Bharati en la India, premiaron su labor otorgándole condecoraciones y doctorados honoris causa. Sut fama ha trascendido todas las fronteras. Hace diez años, Eugenio Montale, en Milán, me preguntó: «¿Y cómo está Victoria Ocampo?», y no la había visto en su vida.

Sin perder nunca de vista su postura frente a la situación social de la mujer, en 1936 fundó la Unión Argentina de Mujeres y en 1971 apareció un extenso número de Sur sobre la mujer, que Victoria dedicó a la memoria de su antepasada guaraní, Agueda, y de su amiga Virginia Woolf. Entre las colaboraciones figuraban desde Golda Meier hasta Indira Gandhi. Había, además, dos encuestas; en una, mujeres anónimas, sin nombre ni rostro, contestaban lo que podrían llamarse preguntas comprometidas o escabrosas; en la segunda, escritoras, científicas, artistas y periodistas (también yo fui convocada), con nombre y apellido, contestábamos preguntas tan comprometidas y escabrosas como las anteriores; en total, en ese número colaboraron unas ciento cincuenta personas. Victoria insiste, en todas las formas posibles, en aquel sabio párrafo de San Agustín: «Si Dios hubiera querido que la mujer gobernara al hombre, 
la habría extraído de la cabeza, y de sus pies de haberla destinado a ser su esclava; pero Dios sacó a la mujer del costado del hombre porque quiso que fuera su compañera y su igual.»

Al decir de Enrique Pezzoni: «La imponente figura de Victoria Ocampo ofusca su verdadera imagen, la de la escritora. Ella insiste una y otra vez en denunciar su incapacidad para escribir literatura de creación: habría deseado escribir novelas, pero no era mi sino, diría, y aclarará en otra ocasión: No escribo poemas, aunque todo el mundo que me circunda, por humilde y aparentemente prosaico que sea, me parece materia poética, ya que la siento misteriosa. Lo cierto es (continúa Pezzoni) que el poeta y el novelista organizan y conforman la realidad y, en cierto modo, la reemplazan para instaurar un nuevo orden que encarna la visión del mundo. Para ello, la realidad es tan sólo materia inerte, a la espera de combinaciones. Para Victoria Ocampo, enfrentar la realidad es desentrañarle un sentido que ya está en ella, pero que es preciso buscarle sin alterarla, sin destruir los sutiles enlaces entre las simples apariencias y ese misterio final en que todos se reúnen.»

Victoria Ocampo ha escrito varios libros de crítica y de evocaciones: Lawrence de Arabia, Virginia Woolf, Keyserling, Tagore, Bach... fueron sus temas. En 1958 realizó una nueva experiencia en el ámbito teatral, esta vez con la creación de un texto de «luz y sonido», Habla el algarrobo, dedicado al algarrobo histórico de San Isidro... Pero lo más importante de su obra se halla en los diez volúmenes que llevan el título de Testimonios, y que son, en realidad, la descripción de la época que le tocó vivir y de la gente que ha conocido. La prosa de Victoria Ocampo puede resultar fascinante y cautivadora. Ella es, en el fondo, una cronista de su tiempo e interesa lo que narra y como lo narra. Dice Borges: «Le interesaba el universo. Apreciaba y agradecía la infinita variedad de las almas, la circunstancia de que cada una fuera única. Fue acusada de anglófila y de francófila, como si el hecho de querer a algo fuera una culpa. Fue una lectora hedónica: leía a Shakespeare o a Dante con la misma curiosidad con que leía a Valéry o a Virginia Woolf. Poseyó, en grado sumo, la gracia que no quiso darme el cielo, el don de la confidencia siempre íntima y nunca indiscreta, que es el atractivo esencial de sus Testimonios." Si la obra de Victoria Ocampo juega a no ser más que una confidencia, como afirmó Borges, cabe agregar que cada lector es el destinatario de esas confidencias, que incluyen un juicio certero, una sinceridad absoluta, una ironía limpia y una increíble capacidad para asombrarse ante el mundo, que Victoria conservó hasta los últimos días de su larga vida. Con cada lector, del que hace un amigo, comparte desde su fascinación por la Divina Comedia hasta su diálogo 
con Malraux, su admiración por Gandhi y su desprecio por los mercenarios. En este compartir traza la gran crónica de nuestra ciudad, de nuestro país, de nuestro mundo contemporáneo.

Las dos últimas apariciones públicas de Victoria configuran dos momentos muy importantes de su vida; la primera, cuando la Academia Argentina de Letras la incorporó como miembro de número (ella será la primera y hasta ahora única mujer académica), y la segunda, cuando tuvo lugar el denominado Diálogo de las Culturas. Con su infaltable flor en la solapa, defendiéndose de los fotógrafos detrás de sus anteojos negros, Victoria fue la dueña absoluta de la atención y de la voluntad de la multitud que colmaba el espléndido salón del Palacio Errázuriz de la Academia. Habló, una vez más, de su antepasada guaraní y de Gabriela Mistral, de su iniciación en las letras, de Sur y del arduo camino que tuvo que recorrer hasta ese momento en que ingresaba en la Academia. Al terminar su exposición en el Errázuriz, una ovación coronó sus palabras.

E1 Diálogo de las Culturas se realizó en Villa Ocampo, en San Isidro, en la gran casa que fue de sus mayores, donde ella vivía y que donó a la Unesco. Estaban allí, alrededor de la mesa, los representantes más destacados del pensamiento moderno: el colombiano Germán Arciniegas, los españoles Francisco Ayala y Julián Marías, el francés Roger Caillois, Alionne Diop del Senegal, Von Keyserling, el ensayista japonés Tadeo Takemoto, el poeta libanés Salah Stétie, el venezolano Juan Liscano, los argentinos Víctor Massuh, el padre Ismael Quiles, Fryda Schultz de Mantovani, Angel Battisttesa y el subdirector general de cultura de la Unesco, Allhudin Bammate. Victoria, que intervino varias veces, hizo hincapié en las dificultades de dialogar y en los problemas terminológicos y metodológicos que plantea la noción misma de la cultura. Este fue el primer encuentro que la Unesco realizó en Villa Ocampo; se trataron los temas más candentes de nuestras culturas y la reunión fue un éxito, pero todos tuvieron la sensación de que la gran homenajeada era Victoria Ocampo.

La última vez que vi a Victoria (ella me había mandado 1lamar, me escribió una carta invitándome a tomar el té en su casa de San Isidro) fue la primera semana de agosto de 1978. Me recibió en la cama. Había adelgazado, la piel transparente y delicada y los ojos vivaces, grandes y violetas, sin la barrera de los anteojos, le daban un aire juvenil. Llevaba unos aros de perlas y el pelo recogido sobre la nuca con una cinta. Todo a su alrededor era alegre y armonioso. Al alcance de la mano tenía un espejo y, de vez en cuando, se miraba subrepticiamente. Con humor y alegría me comentaba conversaciones que había tenido con otros visi- 
tantes y se interesaba por libros nuevos y, sobre todo, me hacía preguntas... Cuando me levanté para irme, me estrechó las manos y las retuvo un momento entre las suyas. Afuera anochecía y una bruma helada subía del río, desdibujando los árboles y el jardín. La casa empezó a alejarse entre la niebla. Levanté la cabeza, pero ya no se veían las ventanas del piso alto. Era como si el jardín, la casa y la señora de la casa fueran entrando en una dimensión misteriosa y vedada. Sin embargo, todavía recibí dos cartas de ella, muy breves. La última empezaba así: «Las tres de la mañana, como siempre con insomnio.»

Victoria murió el 27 de enero. Trabajó y estuvo atenta a todo durante el jueves 25 y el viernes 26. Esos dos días se recibieron en Villa Ocampo a los postulantes para traductores de 1a Unesco. Ella, desde su cuarto en la planta alta, desde su cama, seguía paso a paso las peripecias de los exámenes.

Como sucede a menudo, cuando muere alguien a quien se ha querido, al transcurrir las semanas y los meses, que alejan el momento de su muerte, ese alguien empieza a adornarse con virtudes que a veces tenía y que otras le adjudicamos. El caso de Victoria Ocampo es distinto. Ella fue una mujer valiosa y valerosa que estructuró su destino. Ella dedicó el quehacer de su mítica y prodigiosa vida a lograr que nuestro querido país, el que está más al sur de América, accediera, sin perder su sentido americano, al vasto mundo que los hombres comparten, al infinito mundo que Dios ha creado para felicidad de sus criaturas.

Buenos Aires, abril de 1979.

María Esther VÁzouez 
